06

\title{
Исследование трещиностойкости покрытий микродугового оксидирования после лазерного легирования оксидом циркония
}

\author{
() В.А. Лапицкая, ${ }^{1}$ T.А. Кузнецова, ${ }^{1}$ С.А. Чижик, ${ }^{1}$ А.И. Комаров, ${ }^{2}$ Ю.И. Фролов, ${ }^{3}$ А.С. Романюк ${ }^{2}$ \\ ${ }^{1}$ Институт тепло- и массообмена им. А.В. Лыкова НАН Беларуси, \\ 220072 Минск, Беларусь \\ ${ }^{2}$ Объединенный институт машиностроения НАН Беларуси, \\ 220072 Минск, Беларусь \\ ${ }^{3}$ Белорусский национальный технический университет, \\ 220013 Минск, Беларусь \\ e-mail: vasilinka.92@mail.ru
}

Поступило в Редакцию 28 марта 2019 г.

В окончательной редакции 28 марта 2019 г.

Принято к публикации 15 апреля 2019 г.

Представлены результаты исследования трещиностойкости покрытия микродугового оксидирования (МДО) после лазерного легирования оксидом циркония. Трещиностойкость определяли методом индентирования с визуализацией отпечатка с помощью атомно-силовой микроскопии. Установлено, что лазерное легирование оксидом циркония приводит к значительному упрочнению МДО-покрытия. Коэффициент интенсивности напряжений в 2.7 раз увеличивается, и повреждаемость поверхности в 2 раза уменьшается по сравнению с исходным МДО-покрытием.

Ключевые слова: трещиностойкость, микродуговое оксидирование, покрытие, лазерное легирование, атомно-силовая микроскопия.

DOI: 10.21883/JTF.2019.11.48331.117-19

\section{Введение}

Керамические покрытия, полученные микродуговым оксидированием (МДО) алюминия, благодаря высоким механическим, изоляционным, теплофизическим характеристикам и эксплуатационным свойствам в настоящее время широко используются в машиностроении, в приборостроении, радиоэлектронике, авиационной и космической отраслях, в нефтегазодобывающей промышленности. Для повышения прочности МДО-покрытий применяют такие методы, как добавление дисперсных нано-размерных частиц в электролит при формировании покрытия, обработку лазерным излучением и др. [1-3].

Одним из основных физико-механических свойств керамических покрытий является трещиностойкость и ее контроль на ответственных изделиях обязателен. Трещиностойкость определяют различными методами (изгибом, скалыванием, индентированием), но не все можно применить к покрытиям. Распространенным методом определения трещиностойкости покрытия является метод индентирования путем внедрения пирамиды Виккерса в поверхность покрытия с последующим измерением параметров отпечатков и длины радиальных трещин у отпечатков [4]. Количественно трещиностойкость характеризуется критическим коэффициентом интенсивности напряжений $K_{1 C}$. Выбор правильного подхода и формулы расчета $K_{1 C}$ при методе индентирования зависит от вида формирующихся трещин и отношения длины трещины $c$, к длине полудиагонали отпечатка $a$ [4]. Традиционно для количественного определения длины трещин ис- пользуется оптическая микроскопия, а в редких случаях сканирующая электронная микроскопия (СЭМ) [5,6].

Для точного детектирования параметров отпечатка микротвердости и определения вида трещин на поверхности отпечатка перспективно использование метода атомно-силовой микроскопии (АСM) [7-12]. Совмещение АСМ с методами локального механического деформирования позволяет выявить характеристики фаз материалов и тонких покрытий, не определяемые традиционной техникой [13-16]. Метод АСМ позволяет изучать структуру поверхности с вертикальным разрешением до ангстрем, что позволяет по топографии поверхности выявлять особенности деформации и разрушения материала, не определяемые ни оптикой, ни СЭМ. При малых нагрузках погрешность определения длины трещин и параметров отпечатка оптическим методом по сравнению с АСМ достигает 30\% (из них 20\% определение длины трещины и $10 \%$ - определение длины диагонали отпечатка) [17].

Целью настоящей работы являлось определение критического коэффициента интенсивности напряжений $K_{1 C}$ МДО-покрытия после лазерного легирования оксидом циркония методом индентирования с визуализацией отпечатков при помощи АСМ.

\section{Методика эксперимента}

Микродуговое оксидирование образцов из алюминиевого сплава В95 проводилось в силикатно-щелочном 

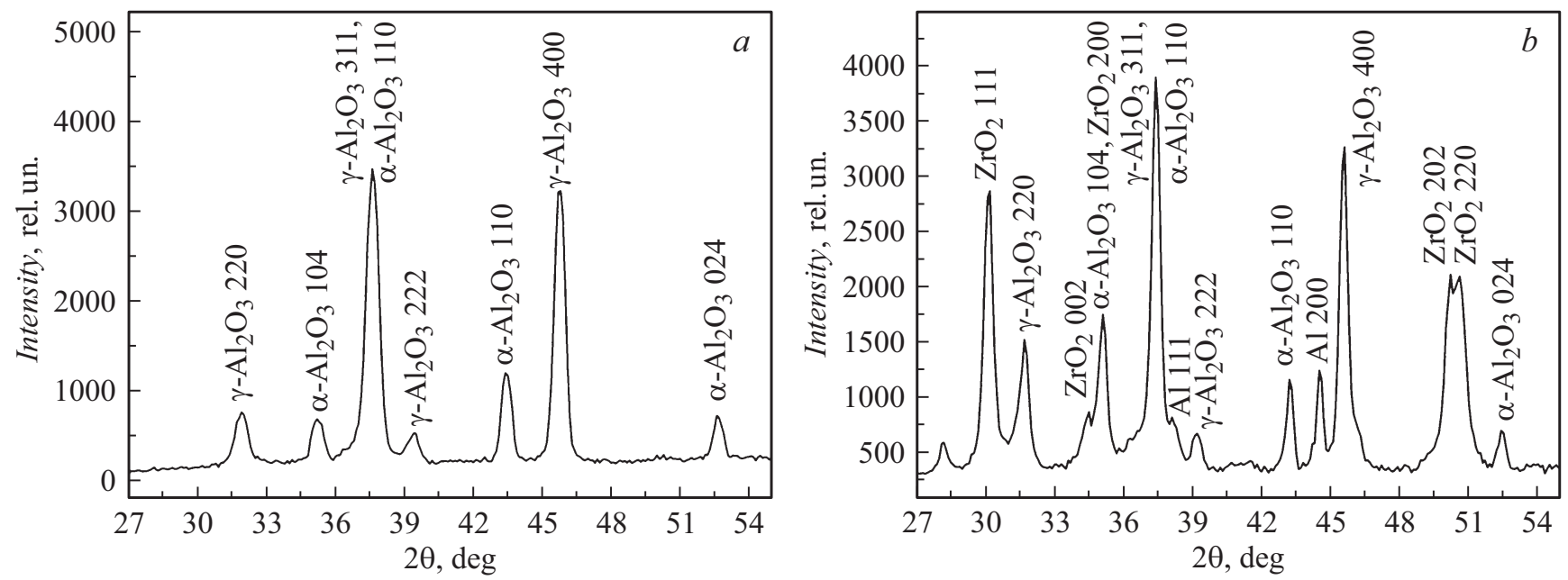

Рис. 1. Фрагменты дифрактограмм МДО-покрытия в исходном состоянии $(a)$ и после лазерного легирования оксидом циркония $(b)$.

электролите на основе дистиллированной воды с концентрацией натриевого жидкого стекла $\mathrm{Na}_{2} \mathrm{SiO}_{3}-4 \mathrm{~g} / 1$, гидроксида калия КОН - $2 \mathrm{~g} / 1$ в анодно-катодном режиме при плотности тока $55 \mathrm{~A} / \mathrm{dm}^{2}$ в течение $90 \mathrm{~min}$. Затем осуществлялась обработка керамического покрытия лазерным излучением с применением легирующей обмазки $\mathrm{ZrO}_{2}$. Параметры лазерной обработки были следующие: мощность излучения 1 кW, диаметр луча $3 \mathrm{~mm}$, скорость перемещения луча $400 \mathrm{~mm} / \mathrm{min}$ [18]. Рентгеноструктурные исследования покрытий проводились на автоматизированном комплексе на базе дифрактометра ДРОН-3М в $\mathrm{Cu} K_{\alpha}$-излучении с применением вторичной монохроматизации рентгеновского пучка при пошаговой $\left(0.1^{\circ}\right)$ съемке с продолжительностью набора импульсов в каждой точке $20 \mathrm{~s}$.

Для исследования использовали шлиф поперечного сечения образца с МДО-покрытием после лазерного легирования оксидом циркония. Отпечатки наносили с помощью микротвердомера ПМТ-3 (Россия). Нагрузка на индентор составляла $10,20,30,50,100,200,300$ и $500 \mathrm{~g}(0.098,0.196,0.294,0.49,0.981,1.961,2.941$ и $4.903 \mathrm{~N}$ соответственно).

Морфологию поверхности отпечатков исследовали на ACM Dimension FastScan (Bruker, CША) в режиме PeakForce Tapping QNM с использованием стандартных кремниевых кантилеверов типа NSC-11 (производство MicroMash, Эстония) с радиусом кривизны острия зонда $12.2 \mathrm{~nm}$ и жесткостью консоли $6.74 \mathrm{~N} / \mathrm{m}$. Оценку радиуса кривизны острия зонда определяли с помощью эталонного образца RS-12M - образца шероховатости поликристаллического титана.

Коэффициент интенсивности напряжений $K_{1 C}$ определяли по формулам (1)-(3) [3,19]. Формула (1) одна из самых простых в расчетах, однако не всегда правильно проводить расчет $K_{1 C}$ без учета модуля упругости и микротвердости образца. Формула (2) - универсальная для расчета $K_{1 C}$ в любых материалах. Формула (3) - формула Ниихары [20] - одна из первых формул, полученная для определения трещиностойкости материалов, учитывающая все параметры контакта: прикладываемую нагрузку, модуль упругости, длину полудиагонали отпечатка и длину образовавшихся трещин:

$$
\begin{gathered}
K_{1 C}=0.0752 \frac{P}{c^{\frac{3}{2}}}, \\
K_{1 C}=0.016\left(\frac{E}{H_{V}}\right)^{\frac{1}{2}} \frac{P}{c^{\frac{3}{2}}}, \\
K_{1 C}=0.067 H_{V} a^{\frac{1}{2}}\left(\frac{E}{H_{V}}\right)^{\frac{2}{5}}\left(\frac{c}{a}\right)^{\frac{3}{2}},
\end{gathered}
$$

где $K_{1 C}-$ коэффициент интенсивности разрушения $\left[\mathrm{MPa} \cdot \mathrm{m}^{1 / 2}\right] ; P$ - нагрузка на индентор $[\mathrm{N}] ; E-$ модуль упругости $[\mathrm{GPa}] ; H_{V}-$ твердость по Виккерcy $[\mathrm{GPa}] ; a$ - длина полудиагонали отпечатка $[\mu \mathrm{m}] ; c-$ длина радиальных трещин около отпечатка $[\mu \mathrm{m}]$.

Повреждаемость поверхности покрытия определяли как отношение микротвердости $H_{V}$ к коэффициенту интенсивности напряжений $K_{1 C}$. Данное отношение характеризует способность материала сопротивляться механическим повреждениям его поверхности [21].

\section{Результаты и их обсуждение}

Согласно результатам рентгеноструктурного анализа, фазовый состав исходного МДО-покрытия (рис. 1,a) представлен оксидом алюминия $\gamma-\mathrm{Al}_{2} \mathrm{O}_{3}$ в кубической (ГЦК) и гексагональной $\alpha-\mathrm{Al}_{2} \mathrm{O}_{3}$ сингониях, при этом преимущественной фазой является низкотемпературная форма $\gamma-\mathrm{Al}_{2} \mathrm{O}_{3}$. Лазерное легирование приводит к включению в состав МДО-покрытия оксида циркония в тетрагональной форме (рис. $1, b)$. По выполненной оценке содержание оксида циркония $\mathrm{ZrO}_{2}$ в поверхностном 

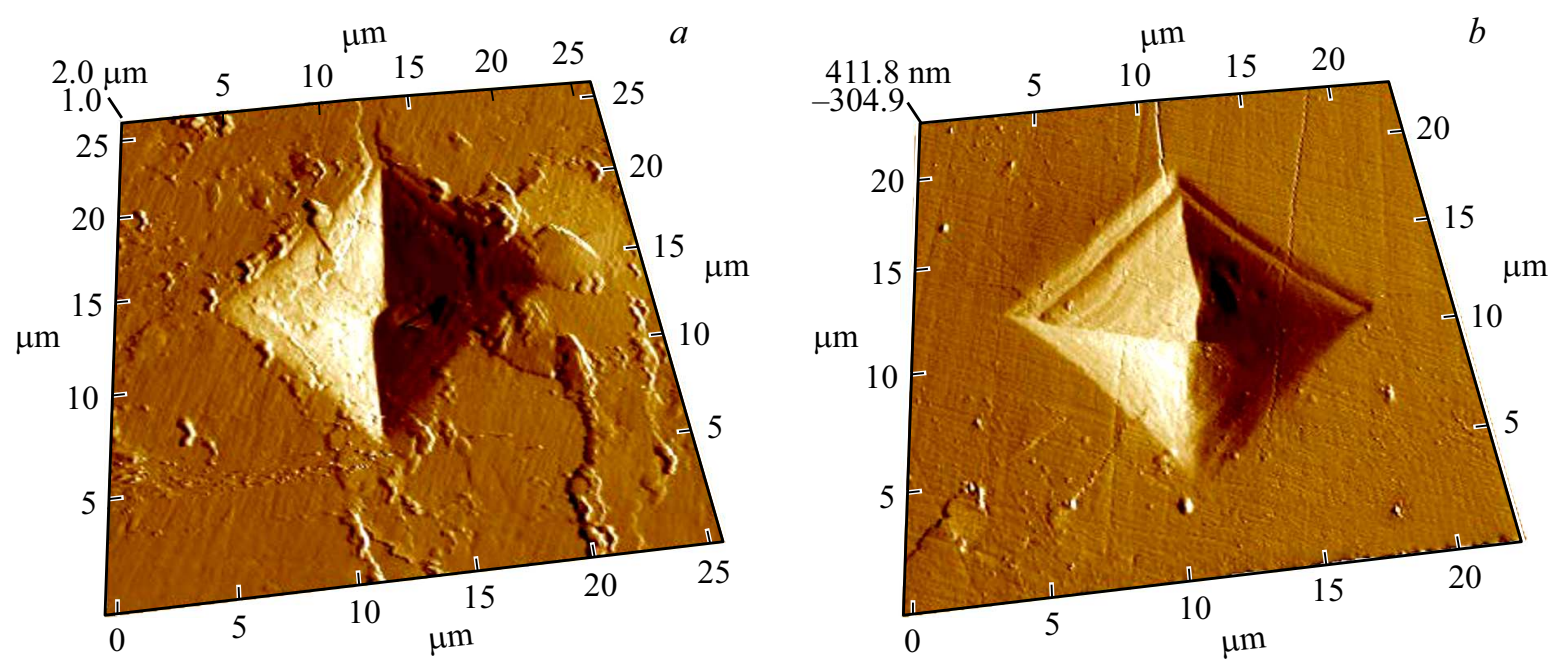

$c$
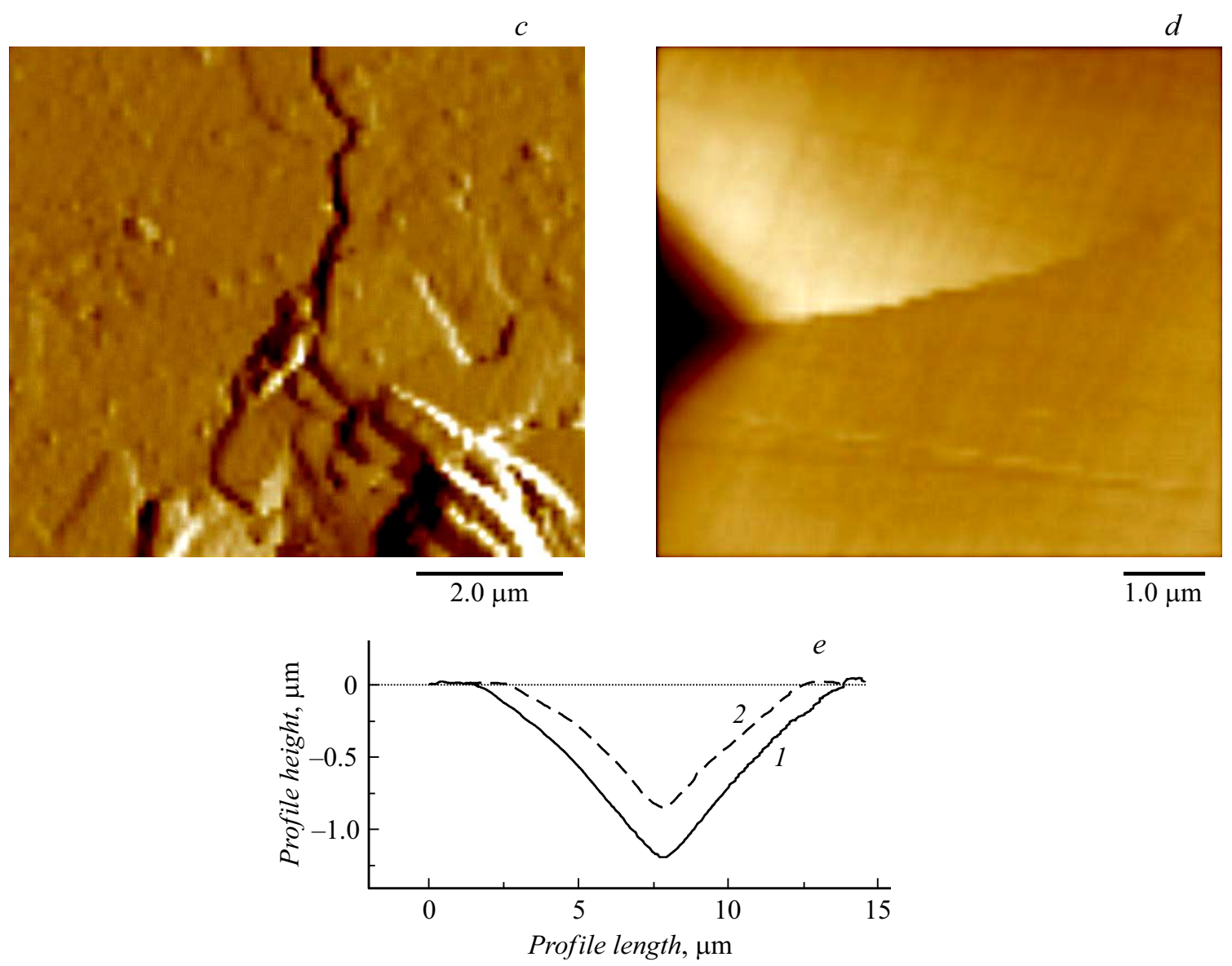

Рис. 2. АСМ-изображения поверхности отпечатков индентирования (поле сканирования $25 \times 25 \mu \mathrm{m}$ ): $a$ - исходное МДО-покрытие (нагрузка $1.961 \mathrm{~N}) ; b-$ МДО-покрытие после лазерного легирования оксидом циркония (нагрузка $1.961 \mathrm{~N}) ; c-$ вид трещины на МДО-покрытии (нагрузка $0.981 \mathrm{~N}) ; d$ - вид трещины на МДО-покрытии после лазерного легирования оксидом циркония (нагрузка $0.981 \mathrm{~N}) ; e$ - профили отпечатков (нагрузка $1.961 \mathrm{~N}) .1$ - исходное МДО-покрытие, 2 - МДО-покрытие с $\mathrm{ZrO}_{2}$ после переплавки.

слое достигает 50\%. В модифицированном покрытии также регистрируются отражения алюминиевой основы, появление которых может быть связано с образованием сквозных пор в результате переплава покрытия в процессе его лазерной обработки [18].
Методом АСМ исследована морфология отпечатков МДО-покрытия после лазерного легирования оксидом циркония (рис. 2, $a, b$ ). По полученным АСМ-изображениям поверхности отпечатков установлено, что лазерное легирование приводит к упрочнению МДО-пок- 
Таблица 1. Результаты определения средней длины диагонали отпечатка, глубины внедрения индентора и средней длины трещины методом АСM

\begin{tabular}{|c|c|c|c|c|c|c|}
\hline \multirow{2}{*}{$\begin{array}{c}\text { Нагрузка } \\
P, \mathrm{~N}\end{array}$} & \multicolumn{2}{|c|}{$\begin{array}{c}\text { Средняя длина } \\
\text { диагонали отпечатка, } \\
d_{\mathrm{av}}, \mu \mathrm{m}\end{array}$} & \multicolumn{2}{|c|}{$\begin{array}{l}\text { Средняя длина } \\
\text { трещины } c, \mu \mathrm{m}\end{array}$} & \multicolumn{2}{|c|}{$\begin{array}{c}\text { Глубина внедрения } \\
\text { (АСМ), } \mu \mathrm{m}\end{array}$} \\
\hline & $\begin{array}{c}\text { МДО- } \\
\text { покрытие }\end{array}$ & $\begin{array}{c}\text { МДО- } \\
\text { покрытие с } \\
\mathrm{ZrO}_{2}\end{array}$ & $\begin{array}{c}\text { МДО- } \\
\text { покрытие }\end{array}$ & $\begin{array}{c}\text { МДО- } \\
\text { покрытие с } \\
\mathrm{ZrO}_{2}\end{array}$ & $\begin{array}{c}\text { МдО- } \\
\text { покрытие }\end{array}$ & $\begin{array}{c}\text { МДО- } \\
\text { покрытие с } \\
\mathrm{ZrO}_{2}\end{array}$ \\
\hline 0.098 & 5.55 & 5.46 & 0 & 0 & 0.40 & 0.31 \\
\hline 0.196 & 6.37 & 6.29 & 2.22 & 0 & 0.44 & 0.38 \\
\hline 0.294 & 7.58 & 6.64 & 3.12 & 0 & 0.61 & 0.46 \\
\hline 0.490 & 8.99 & 7.99 & 4.74 & 0 & 0.69 & 0.60 \\
\hline 0.981 & 12.26 & 10.83 & 7.24 & 3.50 & 1.10 & 0.85 \\
\hline 1.961 & 15.43 & 14.63 & 12.13 & 5.91 & 1.38 & 1.21 \\
\hline 2.941 & 20.76 & 18.26 & 16.35 & 8.09 & 1.86 & 1.59 \\
\hline
\end{tabular}

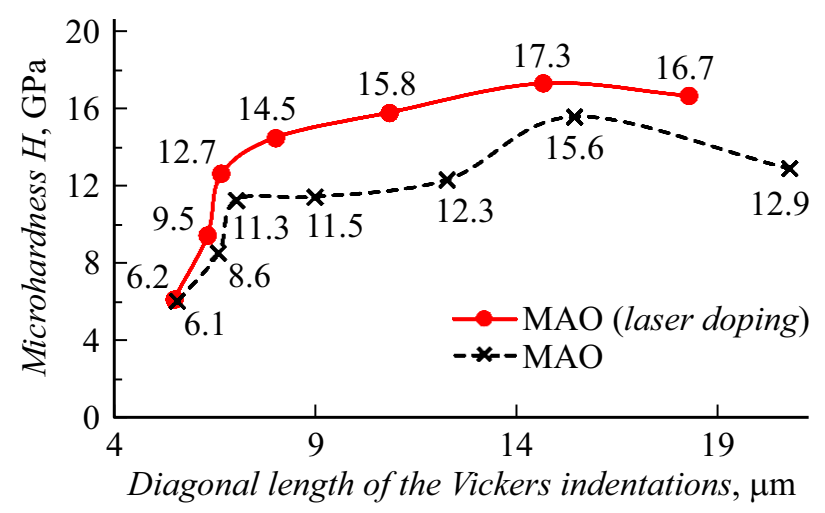

Рис. 3. Зависимость микротвердости покрытий от длины диагонали отпечатка.

рытия и улучшению его стойкости к образованию трещин. Так, на исходном МДО-покрытии трещины появляются уже при нагрузке $0.196 \mathrm{~N}$ (табл. 1). На покрытии с лазерным легированием трещины появляются только при нагрузке $0.981 \mathrm{~N}$. Средняя длина образовавшихся трещин при нагрузке $0.981 \mathrm{~N}$ на покрытии с лазерным легированием в 2 раза меньше, чем на исходном МДО-покрытии (рис. 2,c,d). Трещины на исходном МДО-покрытии более развитые и имеют большую ширину раскрытия (рис. 2,c). Раскрытие трещин и глубина отпечатков хорошо контролируется профилем сечения поверхности АСМ (рис. 2,e).

При максимальной исследованной нагрузке $4.903 \mathrm{~N}$ и на исходном покрытии, и на покрытии с лазерным легированием происходит скалывание и отделение материала по линиям распространения трещин.

На рис. 3 показана зависимость изменения микротвердости исследуемых покрытий от длины диагонали отпечатка. Как следует из представленных данных, микротвердость на участке при нагрузках от 0.981 до $2.941 \mathrm{~N}$ практически стабилизируется (на графике соответствует длине диагонали от 10 до $19 \mu \mathrm{m})$. Полученные результаты свидетельствуют также о повышении микротвердости покрытия в результате его лазерного легирования. Так,
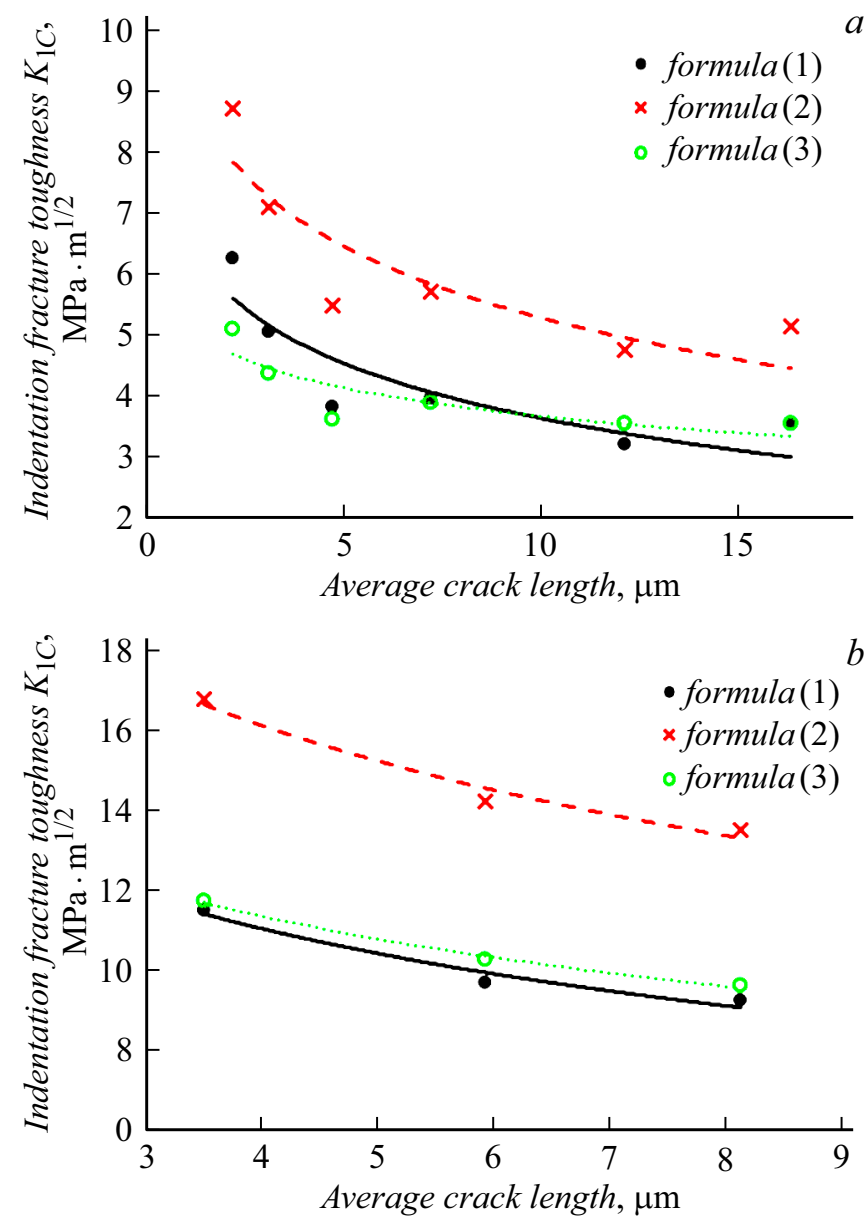

Рис. 4. Зависимость коэффициента интенсивности напряжений $K_{1 C}$ от средней длины трещины для: $a-$ исходного МДО-покрытия (при нагрузках 0.196-2.941 N); $b-$ МДОпокрытие после лазерного легирования оксидом циркония (при нагрузках $0.981-2.941 \mathrm{~N})$. 

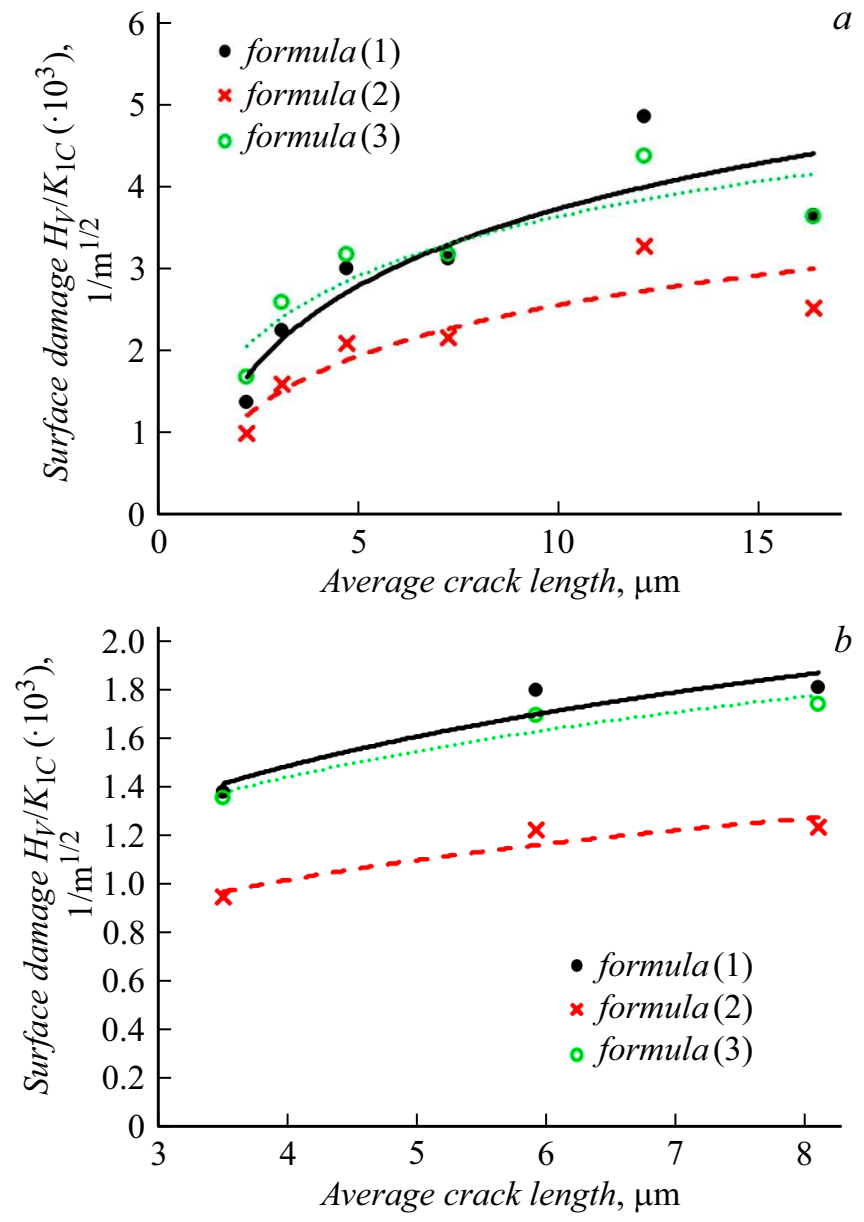

Рис. 5. Повреждаемость поверхности для: $a-$ исходного МДО-покрытия (при нагрузках 0.196-2.941 N); $b-$ МДОпокрытие после лазерного легирования оксидом циркония (при нагрузках $0.981-2.941 \mathrm{~N})$.

Таблица 2. Значения коэффициента интенсивности напряжений $K_{1 C}$, микротвердости и повреждаемости поверхности покрытий

\begin{tabular}{l|c|c|c}
\hline Покрытие & $H_{V}, \mathrm{GPa}$ & $\begin{array}{c}\text { Коэффициент } \\
\text { интенсивности } \\
\text { напряжений } K_{1 C}, \\
\mathrm{MPa} \cdot \mathrm{m}^{1 / 2}\end{array}$ & $\begin{array}{c}\text { Повреждаемость } \\
\text { поверхности } \\
H_{V} / K_{1 C}, \\
10^{3} / \mathrm{m}^{1 / 2}\end{array}$ \\
\hline МДО-покрытие & 13.6 & 3.6 & 3.7 \\
\hline $\begin{array}{l}\text { МДО-покрытие } \\
\text { после лазерного } \\
\begin{array}{l}\text { легирования } \\
\text { оксидом } \\
\text { циркония }\end{array}\end{array}$ & 16.6 & 9.7 & 1.6 \\
\end{tabular}

среднее значение микротвердости исходного МДО-покрытия составило $13.6 \mathrm{GPa}$, а МДО-покрытия после лазерного легирования оксидом циркония $-16.6 \mathrm{GPa}$ (рис. 3).
Результаты определения коэффициента интенсивности напряжений $K_{1 C}$ по формулам (1)-(3) и его зависимость от длины образовавшихся трещин приведена на рис. 4.

Из данных, представленных на графиках, следует, что значительного различия при расчетах по формулам (1), (2) и (3) в количественном изменении $K_{1 C}$ нет. C ростом нагрузки при индентировании $K_{1 C}$ уменьшается и при нагрузках $0.981-2.941 \mathrm{~N}$ изменяется несущественно. Таким образом, среднее значение $K_{1 C}$ составило (табл. 2): для исходного МДО-покрытия $3.6 \mathrm{MPa} \cdot \mathrm{m}^{1 / 2}$, для МДО-покрытия после лазерного легирования оксидом циркония $9.7 \mathrm{MPa} \cdot \mathrm{m}^{1 / 2}$.

Также было определена повреждаемость поверхности покрытия (табл. 2). По построенной зависимости повреждаемости поверхности покрытия от длины трещины (рис. 5) установлено, что повреждаемость поверхности исходного МДО-покрытия в 2 раза выше, чем у МДОпокрытия после лазерного легирования оксидом циркония.

Коэффициент повреждаемости для исходного МДОпокрытия составил $3.7 \cdot 10^{3} 1 / \mathrm{m}^{1 / 2}$, а для МДО-покрытия после лазерного легирования оксидом циркония $1.6 \cdot 10^{3} 1 / \mathrm{m}^{1 / 2}$.

\section{Заключение}

Методом рентгенофазового анализа установлено, что лазерное легирование МДО-покрытия оксидом циркония приводит к образованию композиционного керамического слоя, состоящего из оксида алюминия в модификациях $\gamma-\mathrm{Al}_{2} \mathrm{O}_{3}$ и $\alpha-\mathrm{Al}_{2} \mathrm{O}_{3}$ и оксида циркония в тетрагональной форме.

Методом АСМ исследована трещиностойкость МДОпокрытия после лазерного легирования оксидом циркония, определены коэффициент интенсивности напряжений и повреждаемость поверхности покрытий.

Коэффициент интенсивности напряжений, характеризующий трещиностойкость, МДО-покрытия после лазерного легирования оксидом циркония в 2.7 раз выше, чем у исходного МДО-покрытия и составил: для исходного МДО-покрытия $3.6 \mathrm{MPa} \cdot \mathrm{m}^{1 / 2}$, для МДО-покрытия после лазерного легирования оксидом циркония $9.7 \mathrm{MPa} \cdot \mathrm{m}^{1 / 2}$. Показано, что повреждаемость поверхности покрытия с лазерным легированием в 2 раза ниже, чем на исходном МДО-покрытии.

Установлено, что лазерное легирование оксидом циркония приводит к значительному упрочнению МДОпокрытия и расширяет возможности использования данного покрытия в промышленности.

\section{Финансирование работы}

Работа выполнена при поддержке гранта БРФФИ № Ф18P-239. 


\section{Конфликт интересов}

Авторы заявляют, что у них нет конфликта интересов.

\section{Список литературы}

[1] Комаров А.И., Витязь П.А., Комарова В.И., Рожскова Н.Н., Золотая П.С. // Сб. науч. статей: Наноструктуры в конденсированных средах. Минск. 2016. С. 14-20.

[2] Калиниченко А.С., Комаров А.И., Комарова В.И., Мешкова В.В., Искандарова Д.О., Фролов Ю.И. // Современные методы и технологии создания и обработки материалов Сб. науч. труд. в 3 кн. Минск. 2017. С. 176-181.

[3] Витязь П.А., Комаров А.И., Комарова В.И., Кузнещова Т.A. // Трение и износ. 2011. Т. 32. № 4. С. 313-325. [Vityaz P.A., Komarov A.I., Komarova V.I., Kuznetsova T.A. // J. Friction and Wear. 2011. Vol. 32. N 4. P. 231-241. DOI: $10.3103 / \mathrm{S} 106836661104012 \mathrm{X}]$

[4] Anstis G.R., Chantikul P., Lawn B.R., Marshall D.B. // J. Am. Ceram. Soc. 1981. Vol. 64. N. 9. P. 533-538. DOI: 10.1111/j.1151-2916.1981.tb10320.x

[5] Хасанов О.Л., Струи В.К., Соколов В.М., Полисадова В.В., Двилис Э.С., Бикбаева З.Г. Методы измерения микротвердости и трещиностойкости наноструктурных керамик: учебное пособие. Томск: Изд-во Томского политех. ун-та, 2011. $101 \mathrm{c}$.

[6] Дмитриевский А.А., Жигачев А.О., Жигачева Д.Г., Тюрин А.И. // ЖТФ. 2019. Т. 89. Вып. 1. С. 107-111. DOI: $10.21883 /$ JTF.2019.01.46970.102-18

[7] Кузнецова Т.А., Андреев М.А., Маркова Л.В., Чижик С.А. // Трение и износ. 2007. Т. 28. № 3. С. 276-281.

[8] Кузнецова Т.А., Чижик С.А., Худолей А.Л. // Поверхность. Рентгеновские, синхротронные и нейтронные исследования. 2014. № 12. С. 46. DOI: 10.7868/S020735281409011X [Kuznetsova T.A., Chizhik S.A., Khudoley A.L. // J. Surf. Investigation: X-Ray, Synchrotron and Neutron Techniques. 2014. Vol. 8. N 6. P. 1275-1285. DOI: $10.7868 / \mathrm{S} 020735281409011 \mathrm{X}]$

[9] Anishchik V.M., Uglov V.V., Kuleshov A.K., Filipp A.R., Rusalsky D.P., Astashynskaya M.V., Samtsov M.P., Kuznetsova T.A., Thiery F., Pauleau Y. // Thin Solid Films. 2005. Vol. 482. N 1-2. P. 248-252.

DOI: $10.1016 /$ j.tsf.2004.11.153

[10] Andreyev M., Markova L., Kuznetsova T., Anishchik V.M. // Vacuum. 2005. Vol. 78. N 2-4. P. 451-454.

DOI: $10.1016 / j$.vacuum.2005.01.067

[11] Кузнецова Т.А., Андреев М.А., Маркова Л.В. // Материалы, технологии, инструменты. 2006. Т. 11. № 1. С. 105.

[12] Кузнецова Т.А., Андреев М.А., Маркова Л.В. // Трение и износ. 2005. Т. 26. № 5. С. 521-529.

[13] Ulyanova T.M., Titova L.V., Medichenko S.V., Zonov YU.G., Konstantinova T.E., Glazunova V.A., Doroshkevich A.S., Kuznetsova T.A. // Crystallography Reports. 2006. Vol. 51. N SUPPL. 1. DOI: 10.1134/S1063774506070212

[14] Kuznetsova T.A., Lapitskaya V.A., Chizhik S.A., Warcholinski B., Gilewicz A., Kuprin A.S. // IOP Conf. Series: Materials Science and Engineering. 2018. Vol. 443. https://doi.org/10.1088/1757-899X/443/1/012017

[5] Kuznetsova T.A., Lapitskaya V.A., Chizhik S.A., Uglov V.V., Shymanski V.I., Kvasov N.T. // IOP Conf. Series: Materials Science and Engineering. 2018. Vol. 443. https://doi.org/10.1088/1757-899X/443/1/012018
[16] Kuznetsova T.A., Andreev M.A., Markova L.V., Chekan V.A. // J. Friction and Wear. 2001. Vol. 22. N 4. P. 423-428.

[17] Лапицкая В.А., Кузнецова Т.А., Чижик С.А., Гринчук П.С. // Методолог. аспекты скан. зонд. микроскопии: сб. докл. XIII Междунар. конф., Минск, 16-19 окт. 2018. Минск: Беларуская навука, 2018. С. 260-265.

[18] Комаров А.И., Фролов Ю.И., Девойно О.Г., Мешкова B.B. // Актуальные вопросы машиноведения. 2018. Вып. 7. С. 207-213.

[19] Moradkhani A., Baharvandi H., Tajdari M., Latifi H., Martikainen J. // J. Advan. Ceramics. 2013. Vol. 2. N 1. P. 87-102. DOI: $10.1007 / \mathrm{s} 40145-013-0047-\mathrm{z}$

[20] Niihara K., Morena R., Hasselman D.P.H. // J. Mater. Sci. Lett. 1982. Vol. 1. P. 13-16.

[21] Гогоци Г.А., Башта А.В. // Проблемы прочности. 1990. № 9. C. $49-54$. 